\title{
Administração de diferentes concentrações de folhas de Ipomoea asarifolia na ração de camundongos
}

\author{
Administration of different concentrations of leaves of Ipomoea asarifolia in feed of mice
}

\author{
José Radmácyo Gomes Lopes ${ }^{\mathrm{I}}$ Franklin Riet-Correa ${ }^{\mathrm{I}}$ Marcia Alves de Medeiros $^{\mathrm{I}}$ \\ Francelicia Pereira Marques Dantas ${ }^{\mathrm{I}}$ Rosane Maria Trindade Medeiros $^{{ }^{*}}$
}

RESUMO

\begin{abstract}
Considerando que os principais sinais clínicos observados na intoxicação por Ipomoea asarifolia em ruminantes são tremores de intenção e incoordenação, o objetivo deste trabalho foi comprovar se I. asarifolia é tremorgênica para camundongos e o seu efeito sobre o equilíbrio, coordenação motora e força muscular. Três grupos de camundongos machos adultos da linhagem Swiss receberam ração contendo 0, 20\% e $30 \%$ de folhas de I. asarifolia por 30 dias. No dia 0 e a cada cinco dias, foram mensurados o consumo de ração e água e o peso dos animais, realizando-se também testes na trave elevada, suspensão em fio e rota rod. Foram observadas alterações no equilíbrio e na coordenação motora na trave elevada e no rota rod, o que sugere que a planta afeta o sistema nervoso central; porém não ocorreram tremores musculares.
\end{abstract}

Palavras-chave: Ipomoea asarifolia, plantas tóxicas, equilíbrio, coordenação motora.

\section{ABSTRACT}

The main clinical signs observed in the poisoning by Ipomoea asarifolia are intention tremors and incoordination. The aim of this study was to determine if I. asarifolia is tremorgenic for mice and its effect on equilibrium, coordination and muscle strength. Three groups Swiss male mice received ration containing $0,20 \%$ and $30 \%$ of dry I. asarifolia for 30 days. On day 0 and every five days feed and water intake and the weight of the animals were measured. At the same time the animals were tested for equilibrium, coordination and muscle strength on the elevated bar, wire suspension and rota-rod. Changes in balance and motor coordination were observed in the elevated bar and the rotarod, suggesting that the plant affects the central nervous system. However, muscle tremors were not observed.

Key words: Ipomoea asarifolia, toxic plants, equilibrium, motor coordination.

\section{INTRODUÇÃO}

Ipomoea asarifolia é uma planta que causa uma síndrome tremorgênica em ovinos (DÖBEREINER et al., 1960; GUEDES et al., 2007), caprinos (DÖBEREINER et al., 1960; MEDEIROS et al., 2003; GUEDES et al., 2007; ARAÚJO et al., 2008), bovinos (DÖBEREINER et al., 1960; BARBOSA et al., 2005) e bubalinos (BARBOSA et al., 2005). A intoxicação, observada nas regiões Nordeste (MEDEIROS et al., 2003) e Norte (BARBOSA et al., 2005), caracteriza-se por tremores principalmente de cabeça e pescoço. Os tremores inicialmente são finos e discretos, com balançar de cabeça, que podem ser exacerbados quando os animais são movimentados ou assustados. Mais tarde, os animais desenvolvem ataxia cerebelar com tremores severos, andar incoordenado com membros rígidos, hipermetria, balançando quando está em pé e com os membros abertos. Muitos casos não têm lesões histológicas, mas alguns com manifestações clínicas prolongadas apresentam degeneração e perda das células de Purkinje e presença de esferoides axonais na camada granular do cerebelo (GUEDES et al., 2007). Quando os animais são removidos das pastagens, a regressão completa dos sinais clínicos ocorre em 7-15 dias. Até o momento, ainda não se identificou o princípio tóxico da I. asarifolia, porém há algumas hipóteses sobre a natureza do princípio tóxico da salsa, mas nenhuma confirmada. SANTOS (2001), utilizando camundongos como modelo

'Hospital Veterinário, Universidade Federal de Campina Grande (UFGC), Campus de Patos, 58700-970, Patos, PB, Brasil. E-mail: rmtmed@uol.com.br. *Autor para correspondência. 
animal, sugere que a toxina da salsa seja uma lectina de natureza glicoproteica que chamou de lectina tóxica da salsa; no entanto, os sinais observados com a administração endovenosa dessa lectina foram dispneia, convulsões tônico-clônicas e paralisia flácida, seguida de morte, quadro que não tem relação com os sinais neurológicos observados em ruminantes. MEDEIROS et al. (2003) sugerem que o princípio tóxico da $I$. asarifolia seja uma micotoxina ou fitotoxina tremorgênica. Para o estudo da identificação do princípio tóxico da I. asarifolia, bem como o seu mecanismo de ação, faz-se necessário ter um modelo animal, que responda satisfatoriamente à intoxicação pela planta, reproduzindo os sinais observados nos ruminantes. Em um experimento piloto de nosso grupo de pesquisa, foi observado que camundongos que receberam ração contendo $20 \%$ e $30 \%$ de I. asarifolia apresentaram tremores discretos generalizados. Considerando que o principal sinal clínico observado nos ruminantes intoxicados por salsa é o tremor de intenção, o objetivo deste trabalho foi comprovar se I. asarifolia é tremorgênica para camundongos. Além disso, foram estudados os efeitos da I. asarifolia sobre o equilíbrio, coordenação motora e a força muscular de camundongos.

\section{MATERIAL E MÉTODOS}

Foram utilizados 21 camundongos (Mus musculus), machos de linhagem Swiss, com idade de 40 dias, divididos em três grupos homogêneos, sendo dois grupos experimentais e um controle. Os animais eram oriundos de cruzamentos sucessivos no Centro de Criação e Experimentação em Animais de Laboratório (CCEAL-Biotério) do Curso de Medicina Veterinária do Centro de Saúde e Tecnologia Rural da Universidade Federal de Campina Grande, Campus de Patos, PB. Os animais foram alojados, por grupo, em gaiolas de plástico fosco, com tampas metálicas, medindo $30 \times 20 \times 13 \mathrm{~cm}$, mantidas em salas com temperatura ambiente $\left(22-25^{\circ} \mathrm{C}\right)$ controlada por meio de aparelho de ar condicionado, em ciclo de luz natural. A identificação dos animais foi realizada com marcas na cauda, feitas com caneta hidrofóbica $\left(\right.$ Pilot $\left.^{\circledR}\right)$, renovadas semanalmente.

A ração oferecida aos animais foi preparada com folhas de I. asarifolia coletadas nos arredores do Hospital Veterinário da UFCG, secas à sombra por aproximadamente 10 dias, moídas e posteriormente misturadas com ração comercial para camundongos $\left(\right.$ PRESENCE $\left.^{\circledR}\right)$, que também foi moída, nas proporções de 20\% (Grupo 2) e 30\% (Grupo 3). Essa mistura foi homogeneizada manualmente, acrescentando-se
$200 \mathrm{~mL}$ de água e $10 \%$ de amido de milho para se obter a consistência adequada, sendo, em seguida, peletizada artesanalmente com o uso de seringas descartáveis de $20 \mathrm{~mL}$. Após a fabricação, os pellets foram secos à sombra, em temperatura ambiente. Os animais do Grupo 1, controle, receberam ração comercial.

O consumo de ração e de água e o ganho de peso dos animais dos grupos experimentais e controle foram avaliados no primeiro dia de experimento, antes do início da ingestão da planta, e a cada cinco dias até o $30^{\circ}$ dia do experimento. Nesse mesmo período, os animais foram submetidos aos testes de trave elevada, suspensão em fio e rota rod.

O teste de suspensão em fio permite detectar anormalidades neuromusculares mediante a capacidade do animal sustentar seu próprio corpo no fio, o que requer força muscular. $\mathrm{O}$ aparelho utilizado consistia em um fio de cobre de $2 \mathrm{~mm}$ de diâmetro, suspenso horizontalmente entre duas barras de madeira com $40 \mathrm{~cm}$ de altura, dispostas perpendicularmente ao chão e a $80 \mathrm{~cm}$ de distância uma da outra. Na base do equipamento, foi colocada uma caixa plástica contendo maravalha, com o intuito de amortecer o impacto do animal no momento da queda (Figura 1A). Para o teste, o animal era conduzido pelo avaliador até o fio, para que pudesse colocar nele as patas dianteiras. Media-se o tempo total que o animal permanecia no fio. $\mathrm{O}$ cronômetro era parado imediatamente após a queda do animal e o tempo de permanência registrado.

O rota rod é utilizado nos testes para avaliar coordenação motora e equilíbrio. É um dos testes mais utilizados para medir função motora nos roedores, por ser considerado um dos mais sensíveis para isso. Foi utilizado um aparelho Rota Rod automatizado (EFF 411, Insight ${ }^{\mathbb{R}}$ ), que consistia em uma caixa de acrílico com um cilindro de $8 \mathrm{~cm}$ de diâmetro, instalado transversalmente a aproximadamente $20 \mathrm{~cm}$ do piso do equipamento, mantido em rotação através de um motor. A caixa era dividida em quatro baias, de aproximadamente $10 \mathrm{~cm}$ de largura, permitindo a análise de quatro animais simultaneamente (Figura 1B). Para o teste, cada animal era colocado sobre o cilindro já em movimento (velocidade inicial de aproximadamente 10 rotações por minuto), e mediase o tempo que ele conseguia se equilibrar até cair. $\mathrm{Na}$ queda, o cronômetro que verificava o tempo de equilíbrio era automaticamente parado, já que o equipamento possui um sistema instalado no piso de cada baia que detecta o impacto da queda; os animais eram reconduzidos à respectiva baia e o cronômetro reativado, contabilizando o total de quedas ao final 


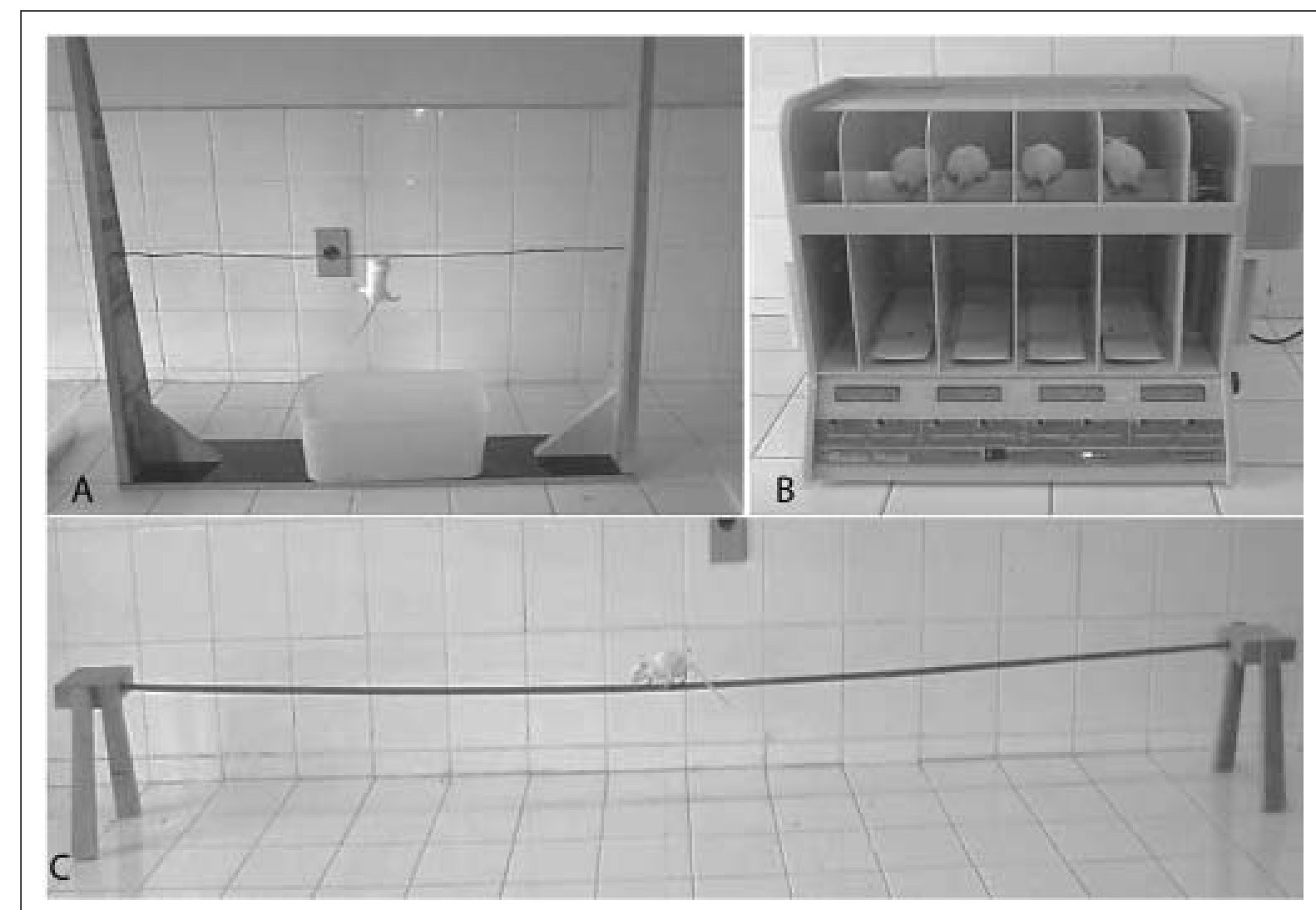

Figura 1- Equipamentos utilizados para avaliar a condição neuromuscular (A: suspensão em fio), equilíbrio e coordenação motora (B: rota rod) e equilíbrio (C: trave elevada).

de seis minutos (velocidade final de 25 rotações por minuto). Foi realizado treinamento prévio dos animais nos dois dias que antecederam o início do experimento. Para isso, cada animal foi colocado para caminhar sobre o cilindro giratório, em rotação mínima, por 2 minutos.

A trave elevada é um equipamento utilizado para avaliar o equilíbrio corporal. Foi usada uma trave elevada adaptada para camundongos, que era constituída por uma trave de madeira $(1 \mathrm{~cm}$ de largura e espessura, por $2 \mathrm{~m}$ de comprimento) apoiada em duas plataformas $(10 \mathrm{~cm} \times 10 \mathrm{~cm}$, cada), uma em cada extremidade, com $20 \mathrm{~cm}$ de altura (Figura 1C). Para o teste, o animal era colocado no centro da trave elevada, cronometrando-se o tempo transcorrido até que chegasse a uma das extremidades do equipamento. Dois dias consecutivos antes do início do experimento, foi realizado um treinamento com os animais no aparelho, onde eram colocados para andar livremente sobre a trave elevada, por 5 minutos.

Os animais que morreram durante o experimento foram necropsiados. No final do experimento, os camundongos restantes dos três grupos foram eutanasiados e necropsiados. Amostras de órgãos das cavidades abdominal e torácica e encéfalo foram coletadas, fixadas em formol tamponado a $10 \%$, incluídas em parafina, cortadas a 4-6 $4 \mathrm{~m}$ e coradas pela Hematoxilina e Eosina. Os resultados obtidos após o estudo das variáveis foram submetidos à análise estatística pelo Teste ANOVA (variáveis com distribuição normal) ou KruskalWallis (variáveis com distribuição não normal), utilizando-se o programa estatístico BioEstat 5.0, adotando-se $95 \%$ de intervalo de confiança.

\section{RESULTADOS}

A comparação estatística do consumo de ração entre os grupos experimentais e controle revelou não haver diferença significante na ingestão de ração (Tabela 1). O consumo de água entre os grupos experimentais e controle apresentou diminuição significante $(\mathrm{P}<0,05)$ nos dois grupos experimentais, quando comparado com o grupo controle (Tabela 1). $\mathrm{O}$ peso foi significativamente menor $(\mathrm{P}<0,05)$ nos animais dos grupos experimentais, comparando-se com aqueles do grupo controle, a partir do $10^{\circ}$ dia de experimento (Tabela 1). 
Tabela 1 - Peso e consumo de ração e água dos camundongos dos grupos experimentais e controle durante o período experimental.

\begin{tabular}{|c|c|c|c|c|c|c|c|c|}
\hline & Grupo & Dia 0 & $5^{\circ} \mathrm{dia}$ & $10^{\circ} \mathrm{dia}$ & $15^{\mathrm{o}}$ dia & $20^{\circ}$ dia & $25^{\mathrm{o}} \mathrm{dia}$ & $30^{\circ} \mathrm{dia}$ \\
\hline \multirow{3}{*}{ Peso $(\mathrm{g})(\mathrm{X} \pm \mathrm{SD})$} & Controle & $33,3 \pm 4,2$ & $33,3 \pm 3,3$ & $34,1 \pm 2,5$ & $35,4 \pm 2,5$ & $35,6 \pm 2,6$ & $36,3 \pm 2,5$ & $36,9 \pm 2,5$ \\
\hline & $20 \%$ de $\mathrm{Ia}^{\mathrm{a}}$ & $31,6 \pm 3,9$ & $28,9 \pm 3,5$ & $28,4 \pm 4,1$ & $28,4 \pm 5$ & $28,6 \pm 5,7$ & $30 \pm 2,9$ & $30,3 \pm 2,9$ \\
\hline & $30 \%$ de Ia & $35,6 \pm 4,3$ & $30,4 \pm 3,6$ & $29,2 \pm 3,6$ & $28,5 \pm 4,6$ & $27,8 \pm 6,1$ & $28,8 \pm 7$ & $29 \pm 7,3$ \\
\hline \multirow{3}{*}{ Água (mL) } & Controle & - & $378^{\mathrm{b}}$ & 325 & 313 & 305 & 282 & 305 \\
\hline & $20 \%$ de Ia & - & 320 & 280 & 260 & 257 & 265 & 252 \\
\hline & $30 \%$ de Ia & - & 201 & 187 & 200 & 207 & 223 & 199 \\
\hline \multirow{3}{*}{ Ração (g) } & Controle & - & $177,7^{\mathrm{b}}$ & 173 & 177,1 & 175,4 & 178,6 & 178,5 \\
\hline & $20 \%$ de Ia & - & 160,5 & 179,9 & 177,6 & 195,9 & 206,3 & 186,2 \\
\hline & $30 \%$ de Ia & - & 123,2 & 168,4 & 169,6 & 175,4 & 186 & 144,4 \\
\hline
\end{tabular}

${ }^{\mathrm{a}} \mathrm{Ia}=$ Ipomoea asarifolia; ${ }^{\mathrm{b}}$ consumo total do grupo.

Foi observada mortalidade apenas nos grupos experimentais. No grupo 2, um animal morreu no $23^{\circ}$ dia do experimento $(14,28 \%)$ e, no grupo 3 , dois animais morreram, sendo um no $18^{\circ}$ dia e outro no $24^{\circ}$ dia do experimento $(28,57 \%)$. Nas necropsias e no estudo histológico, não foram observadas lesões significantes nos animais mortos antes do experimento, assim como nos submetidos à eutanasia no final.

No teste da trave elevada, dois animais do grupo 3 já apresentavam alterações de equilíbrio no primeiro teste realizado, após o início do consumo de ração contendo I. asarifolia (5o dia experimental), caracterizadas pelo andar mais aderido à trave e pelo aumento do tempo na realização do percurso nesta. Com o transcorrer das realizações dos testes, essas alterações aumentaram de intensidade e no número de animais afetados, sendo que, ao final dos 30 dias, todos os animais apresentavam essas alterações de forma intensa. Já no grupo 2, as alterações de equilíbrio citadas anteriormente só foram observadas no segundo teste após o início do consumo de ração contendo I. asarifolia ( $10^{\circ}$ dia experimental), também em dois animais, porém de forma mais branda. No $30^{\circ}$ dia experimental, metade dos animais sobreviventes (3 animais) do grupo 2 apresentavam essas alterações, porém de forma menos acentuada que o grupo 3 . As médias de tempo, que os animais levaram para chegar do meio da trave até a base dela e a análise estatística apresentam-se na tabela 2 .

No teste de suspensão em fio, não se verificou diferença significante na força muscular entre os grupos controle e experimentais (Tabela 3 ). No teste do rota rod, observou-se aumento significante $(\mathrm{P}<0,05)$ no número de quedas nos animais do grupo 3 em relação ao grupo controle (Tabela 4).

\section{DISCUSSÃO}

Os resultados mostraram que as rações contendo $20 \%$ e $30 \%$ de folhas de I. asarifolia foram tóxicas para camundongos adultos, uma vez que foram observadas alterações do equilíbrio e coordenação motora no rota rod e na trave elevada, o que sugere que a planta afeta o sistema nervoso central. No entanto, não foram identificadas alterações na força muscular, o que é evidenciado pelos resultados semelhantes observados entre os grupos no teste da suspensão em fio. Além disso, a toxicidade da planta ficou evidenciada pela diminuição significante no consumo de água e no peso e pela mortalidade nos grupos experimentais. Por outro lado, não foram observados tremores musculares, que é o principal sinal clínico dos ruminantes intoxicados pela planta. Esses resultados foram diferentes dos obtidos em um experimento piloto de nosso grupo de pesquisa, no qual quatro camundongos alimentados com $20 \%$ e $30 \%$ de

Tabela 2 - Média e desvio padrão dos tempos de percurso na trave elevada dos camundongos dos grupos experimentais e controle.

\begin{tabular}{llll}
\hline Dia & Controle & \multicolumn{1}{c}{$20 \%$} & \multicolumn{1}{c}{$30 \%$} \\
\hline 0 & $9,6 \pm 1,5^{\mathrm{a}}$ & $8,9 \pm 2,2 \mathrm{a}$ & $14.3 \pm 4,3 \mathrm{~b}$ \\
$5^{\mathrm{o}}$ & $6,7 \pm 2^{\mathrm{a}}$ & $13,1 \pm 6,7 \mathrm{ab}$ & $18,5 \pm 5,4 \mathrm{~b}$ \\
$10^{\mathrm{o}}$ & $5,4 \pm 1^{\mathrm{a}}$ & $12,4 \pm 14,9 \mathrm{a}$ & $22,9 \pm 10 \mathrm{~b}$ \\
$15^{\mathrm{o}}$ & $5 \pm 1^{\mathrm{a}}$ & $11,4 \pm 7,9 \mathrm{ab}$ & $24,7 \pm 29,5 \mathrm{~b}$ \\
$20^{\circ}$ & $5,1 \pm 3,1^{\mathrm{a}}$ & $8,1 \pm 3,3 \mathrm{ab}$ & $13,2 \pm 5,4 \mathrm{~b}$ \\
$25^{\mathrm{o}}$ & $3,8 \pm 1^{\mathrm{a}}$ & $11,2 \pm 5,7 \mathrm{~b}$ & $13,9 \pm 5,6 \mathrm{~b}$ \\
$30^{\circ}$ & $4,6 \pm 1,1^{\mathrm{a}}$ & $8 \pm 4 \mathrm{ab}$ & $13 \pm 4,6 \mathrm{~b}$ \\
\hline
\end{tabular}

Letras diferentes na mesma linha significam diferença estatística $(\mathrm{P}<0,05)$. 
Tabela 3 - Média e desvio padrão dos tempos de permanência no teste de suspensão em fio dos camundongos dos grupos experimentais e controle.

\begin{tabular}{llll}
\hline Dia & \multicolumn{1}{c}{ Controle } & \multicolumn{1}{c}{$20 \%$} & \multicolumn{1}{c}{$30 \%$} \\
\hline 0 & $87 \pm 6,1 \mathrm{a}$ & $195,6 \pm 225,4 \mathrm{a}$ & $117,8 \pm 106,2 \mathrm{a}$ \\
$5^{\circ}$ & $150,3 \pm 78,9 \mathrm{a}$ & $117,8 \pm 148,4 \mathrm{a}$ & $81 \pm 62,6 \mathrm{a}$ \\
$10^{\circ}$ & $176,5 \pm 165,2 \mathrm{a}$ & $117 \pm 146,1 \mathrm{a}$ & $106,7 \pm 79,3 \mathrm{a}$ \\
$15^{\circ}$ & $222,5 \pm 9,4 \mathrm{a}$ & $131,7 \pm 148,8 \mathrm{a}$ & $152,8 \pm 52,4 \mathrm{a}$ \\
$20^{\circ}$ & $228,2 \pm 115,2 \mathrm{a}$ & $177,8 \pm 119,9 \mathrm{a}$ & $147,1 \pm 60,6 \mathrm{a}$ \\
$25^{\circ}$ & $235,8 \pm 163,5 \mathrm{a}$ & $180,7 \pm 198,2 \mathrm{a}$ & $128,7 \pm 37,1 \mathrm{a}$ \\
$30^{\circ}$ & $252 \pm 96,6 \mathrm{a}$ & $300,83 \pm 130,9 \mathrm{a}$ & $164,6 \pm 99,6 \mathrm{a}$ \\
\hline
\end{tabular}

Letras diferentes na mesma linha significam diferença estatística $(\mathrm{P}<0,05)$.

I. asarifolia na ração apresentaram tremores discretos a partir do terceiro dia de administração. $\mathrm{Na}$ intoxicação por I. asarifolia em ruminantes, os tremores são devidos aparentemente a uma lesão cerebelar mas não ocorrem lesões histológicas, exceto em ovinos com evolução crônica, após muito tempo de ingestão, nos que se observam lesões degenerativas nos neurônios de Purkinje (GUEDES et al., 2007). Neste trabalho, não foram observadas lesões histológicas no cerebelo dos animais intoxicados; no entanto, como ocorre na intoxicação experimental por penitrenos em ratos (LU et al., 2008), possivelmente, sejam necessários estudos de microscopia eletrônica para identificar lesões.

Esses resultados, no seu conjunto, mostram que camundongos são susceptíveis a intoxicação por I. asarifolia e podem ser utilizados como modelo experimental para o estudo da intoxicação. No entanto, o aparecimento de tremores é inconstante. Outros protocolos poderão ser testados em camundongos, como a utilização de animais lactentes, ou em outras espécies, como também a utilização de extratos de I. asarifolia, administrados por vias digestiva ou intraperitoneal. A inoculação de penitren A, substância tremorgênica presente em Lolium perene, causa tremores em ratos quando inoculado pela via intraperitoneal (CAVANAGH et al., 1998; LU et al., 2008) e animais de 1-3 dias de idade são mais susceptíveis que ratos de 11 meses (LU et al., 2008).

\section{CONCLUSÃO}

Conclui-se que Ipomoea asarifolia é tóxica para camundongos adultos, causando alterações motoras e do equilíbrio, porém não causa tremores consistentemente.
Tabela 4 - Média e desvio padrão de quedas no rota rod dos camundongos dos grupos experimentais e controle.

\begin{tabular}{llll}
\hline Dia & Controle & \multicolumn{1}{c}{$20 \%$} & \multicolumn{1}{c}{$30 \%$} \\
\hline 0 & $0,4 \pm 0,8 \mathrm{a}$ & $2,4 \pm 2,3^{\mathrm{a}}$ & $4,1 \pm 4 \mathrm{a}$ \\
$5^{\circ}$ & $0,7 \pm 1,1 \mathrm{a}$ & $3,4 \pm 4 \mathrm{ab}$ & $10,3 \pm 5,4 \mathrm{~b}$ \\
$10^{\circ}$ & $1,3 \pm 0,9 \mathrm{a}$ & $4,4 \pm 4 \mathrm{ab}$ & $12,3 \pm 8,7 \mathrm{~b}$ \\
$15^{\circ}$ & $2,8 \pm 2,3 \mathrm{a}$ & $5,7 \pm 7,8 \mathrm{ab}$ & $14,6 \pm 10,6 \mathrm{~b}$ \\
$20^{\circ}$ & $1,4 \pm 1,9 \mathrm{a}$ & $7 \pm 7,9 \mathrm{ab}$ & $14,5 \pm 12,4 \mathrm{~b}$ \\
$25^{\circ}$ & $1,4 \pm 1,6 \mathrm{a}$ & $3,7 \pm 6.6 \mathrm{a}$ & $22 \pm 27 \mathrm{a}$ \\
$30^{\circ}$ & $1,4 \pm 0,8 \mathrm{a}$ & $3 \pm 6,4 \mathrm{a}$ & $18,4 \pm 21,8 \mathrm{a}$ \\
\hline
\end{tabular}

Letras diferentes na mesma linha significam diferença estatística $(\mathrm{P}<0,05)$.

\section{COMITÊ DE ÉTICA}

Este estudo foi realizado de acordo com os princípios éticos na experimentação animal e aprovado pelo Comitê de Ética no Uso de Animais da UFCG, protocolo CEP n.69-2013.

\section{AGRADECIMENTOS}

Este trabalho foi financiado pelo Instituto Nacional de Ciência e Tecnologia (INCT) Para o Controle das Intoxicações por Plantas, Processo Conselho Nacional de Desenvolvimento Científico e Tecnológico (CNPq) 573534/2008-0.

\section{REFERÊNCIAS}

ARAÚJO, J.A.S. et al. Intoxicação experimental por Ipomoea asarifolia (Convolvulaceae) em caprinos e ovinos. Pesquisa Veterinária Brasileira, v.28, n.10, p.488-494, 2008. Disponível em: $<\mathrm{http}: / /$ www.scielo.br/scielo.php?script=sci arttext\&pid=S0100-736X2008001000008>. Acesso em: 24 jul. 2013. doi: 10.1590/S0100-736X2008001000008.

BARBOSA, J.D. et al. Intoxicação experimental e natural por Ipomoea asarifolia (Convolvulaceae) em búfalos e outros ruminantes. Pesquisa Veterinária Brasileira, v.25, n.4, p.231-234, 2005. Disponível em: $<$ http://www.scielo.br/scielo.php?pid=S0100736X2005000400008\&script $=$ sci arttext $>$. Acesso em: 20 jul. 2013. doi: $10.1590 / \mathrm{S} 0100-736 \times 2005000400008$.

CAVANAGH, J.B. et al. The effects of the tremorgenic mycotoxin Penitrem A on the rat cerebellum. Veterinary Pathology, v.35, p.53-63, 1998. Disponível em: <http://vet.sagepub.com/ content/35/1/53.full.pdf + html $>$. Acessso em: 28 jul. 2013. doi: $10.1177 / 030098589803500105$.

DÖBEREINER, J. et al. Intoxicação experimental pela "salsa" (Ipomoea asarifolia R. et Schult.) em ruminantes. Arquivos do Instituto Biológico Animal, v.3, p.39-57, 1960.

GUEDES, K.M.R. et al. Doenças do sistema nervoso central em caprinos e ovinos no semi-árido. Pesquisa Veterinária Brasileira, v.27, n.1, p.29-30, 2007. Disponível em: <http:// www.scielo.br/scielo.php?script $=$ sci_arttext\&pid $=\mathrm{S} 0100$ 736X2007000100006>. Acesso em: 21 jul. 2013. doi: 10.1590/ S0100-736X2007000100006. 
LU, H. et al. Toxin-produced Purkinje cell death: a model for neural stem cell transplantation studies. Brain Research, v.1207, p.207-213, 2008. Disponível em: <http://www.sciencedirect.com/ science/article/pii/S0006899308003648>. Acessso em: 21 jul. 2013. doi: 10.1016/j.brainres.2008.02.034.

MEDEIROS, R.M.T. et al. Tremorgenic syndrome in goats caused by, Ipomoea asarifolia in northeastern Brazil. Toxicon, v.41, p.933-935, 2003. Disponível em: < http://www.sciencedirect. com/science/article/pii/S0041010103000448>. Acesso em: 28 jul. 2013. doi: 10.1016/S0041-0101(03)00044-8.

SANTOS, L.F.L. Toxina da salsa (Ipomoea asarifolia R. et Schult.): aspectos bioquímicos, estruturais, funcionais e potencial biotecnológico. 2001. 142f. Tese (Doutorado em Bioquímica) Universidade Federal do Ceará, Fortaleza, CE. 